\title{
'H NUCLEAR MAGNETIC RESONANCE SPECTROSCOPY OF YEAST COPPER-ZINC SUPEROXIDE DISMUTASE. STRUCTURAL HOMOLOGY WITH THE BOVINE ENZYME
}

\author{
by \\ ANTHONY E. G. CASS and H. ALLEN O. HILL \\ Inorganic Chemistry Laboratory, University of Oxford, \\ South Parks Road, Oxford, England \\ and \\ VILLY HASEMANN and JACK T. JOHANSEN \\ Department of Chemistry, Carlsberg Laboratory, \\ Gamle Carlsberg Vej 10, DK-2500 Copenhagen Valby
}

Keywords: Superoxide dismutase, ${ }^{1} \mathrm{H}$ n.m.r., Saccharomyces cerevisiae, structural homology, anion binding

\begin{abstract}
High resolution nuclear magnetic resonance (n.m.r.) spectroscopy of the copper-zinc superoxide dismutase from Saccharomyces cerevisiae has revealed a substantial structural homology with the bovine enzyme. N.m.r. spectra of the apo enzyme and the holo-reduced and holo-oxidized enzymes are reported and assignments are made to the histidines in the active site and the single tyrosine residue. All the assignments are in agreement with the known amino-acid sequence and the geometry of the active site is virtually unchanged.

Addition of halide ions to the reduced holo enzyme results in the perturbation of the chemical shift of three histidine $\mathrm{C} 2$ protons and the degree of perturbation is $\mathrm{Cl}^{-} \sim \mathrm{Br}^{-}>\mathrm{I}^{-}>\mathrm{F}^{-}$for $1 \mathrm{M}$ solutions of the anions. The enzyme has also been shown to retain its structure at $75^{\circ} \mathrm{C}$.
\end{abstract}

\section{INTRODUCTION}

There exists a group of metalloenzymes, widely distributed amongst all oxygen metabolizing organisms, whose function is to scavenge the superoxide radical anion, $\mathrm{O}_{2}^{-}$. These enzymes catalyze the dismutation of $\mathrm{O}_{2}^{-}$to hydrogen peroxide and dioxygen:

$$
2 \mathrm{O}_{2}^{-}+2 \mathrm{H}^{+} \rightarrow \mathrm{H}_{2} \mathrm{O}_{2}+\mathrm{O}_{2}
$$

thus affording the organism protection against the toxic effects of this free radical $(15,21)$.

The enzymes isolated from prokaryotes contain either manganese or iron (14) and comparative sequence studies on the $\mathrm{N}$-terminal regions reveals a substantial homology amongst the enzymes from a wide variety of sources (16). 
In contrast, the cytosolic enzymes isolated of eukaryotes usually contain copper and zinc and much more limited sequence data are available. The enzyme from bovine erythrocytes is the best characterized and most intensively studied of this class of proteins and both the complete amino acid sequence (26) and the crystal structure to $3 \dot{A}$ resolution (24) have been published. The enzyme has also been subject to investigation by a variety of physico-chemical techniques, most of which utilize the intrinsic probe properties of the copper (II) ion (11).

In the study of the high resolution ${ }^{1} \mathrm{H}$ nuclear magnetic resonance (n.m.r.) spectra of bovine erythrocyte superoxide dismutase it was shown that the structural data derived from the ${ }^{1} \mathrm{H}$ n.m.r. spectra in solution were consistent with the crystal structure (5). During the course of this work it was possible to assign resonances to groups, both in the active site and at other locations in the molecule $(5,6)$, and to use these as probes of the molecules response to various perturbations (7).

The only other copper-zinc dismutases for which amino acid sequence data are available are those from human erythrocytes (1) and from bakers yeast, Saccharomyces cerevisiae, $(22)^{1}$ and in the present work we use ${ }^{1} \mathrm{H}$ n.m.r. spectroscopy to study how far sequence homology reflects structural similarities between the yeast enzyme and the bovine enzyme.

\section{MATERIALS AND METHODS}

All ${ }^{1} \mathrm{H}$ n.m.r. spectra were obtained at 270 $\mathrm{MHz}$ using a modified Bruker HFX-90 console, 6.4 T superconducting magnet (Oxford Instruments Ltd.) and a Bruker BNC 12 Computer, of the Oxford Enzyme Group. Routinely 1024 free induction decays were accumulated after a $70^{\circ}$ pulse using quadrature phase detection, the excitation pulse was centered on the water fre- quency, and a pulse-to-pulse time of $0.6 \mathrm{~s}$ used. The estimation of peak intensities was made from spectra accumulated after a $90^{\circ}$ pulse, with a pulse-to-pulse time of $5 \mathrm{~s}\left(\sim 5 \mathrm{~T}_{1}\right)$ thus avoiding errors due to different $T_{1}$ values of the resonances (10). Convolution difference spectra were calculated by the method of CAMPBELl et al. (3). Spin echo spectra were obtained by the $90-\tau-180-\tau$-[collect] pulse sequence as previously described (4). For all spectra the deuterium resonance of the solvent $\left(\mathrm{D}_{2} \mathrm{O}\right)$ was used as an internal field-frequency lock and all chemical shifts are quoted in parts per million (p.p.m.) downfield of sodium 2,2-dimethyl2-silapentane-5-sulphonate (DSS) as an internal standard.

Yeast superoxide dismutase was prepared by an improved procedure (HASEMANN et al., to be published). Apo enzyme was prepared by dialysis against EDTA (5). Solutions for n.m.r. spectroscopy were prepared by dissolving the protein in $\mathrm{D}_{2} \mathrm{O}(99.7 \% \mathrm{D})$ and leaving at room temperature for several hours, followed by freeze drying. This cycle of dissolving in $\mathrm{D}_{2} \mathrm{O}$ and freeze drying was performed several times to achieve, as completely as possible, the exchange of labile hydrogen for deuterium. Immediately prior to measuring the n.m.r. spectra samples were dissolved in solutions of $1 \mathrm{M}$-sodium chloride and $20 \mathrm{~mm}$-sodium phosphate in $\mathrm{D}_{2} \mathrm{O}$. The final protein concentration was 80-100 $\mathrm{mg} \cdot \mathrm{ml}^{-1}$.

For the anion binding studies the sodium chloride was replaced by the sodium or potassium salts of the relevant anions. The experiments in which the enzyme was titrated with chloride were performed by dissolving protein samples in sodium chloride/sodium perchlorate mixtures with a constant ionic strength of $1 \mathrm{M}$.

The $\mathrm{pH}$ values of the protein solutions were measured, in the n.m.r. tube, using a Pye Ingold

1. The total amino acid sequence of 153 residues in yeast superoxide dismutase has been determined. Of relevance to this paper is: a) 6 histidine residues from the bovine enzyme are conserved whilst histidines 19 and 41 are missing in the yeast enzyme; b) there are two extra phenylalanine residues in the yeast enzyme substituted for leucine 65 and isoleucine 97 in the bovine enzyme; c) the tyrosine residue is moved from position 108 in the bovine enzyme to position 32 in yeast enzyme (OVERBALLE-PETERSEN et al., to be published).

Abbreviations: n.m.r. = nuclear magnetic resonance; p.p.m. = parts per million; DSS $=2$,2-dimethyl-2-silapentane-5-sulphonate. 
microelectrode and a Radiometer $\mathrm{PH} 26 \mathrm{pH}$ meter and $\mathrm{pH}$ values are quoted as $\mathrm{pH}^{*}$, the direct meter reading uncorrected for the deuterium isotope effect (18). The $\mathrm{pH}^{*}$ values of the solutions were adjusted by addition of 200 $\mathrm{mM}-\mathrm{DCl}$ or $\mathrm{NaOD}$ solutions.

When necessary the protein was reduced from the copper (II) state to the copper (I) state by addition of sufficient solid sodium dithionite to just bleach the colour of the protein. All solutions were prepared with analytical grade chemicals, and water equivalent to a least doubly distilled quality was used throughout.

\section{RESULTS AND DISCUSSION}

\subsection{Apo enzyme}

A convolution difference spectrum of apo yeast superoxide dismutase is shown in Figure 1. Upon increasing the $\mathrm{pH}^{*}$ of the solution, there is an upfield shift of several of the peaks in the aromatic region of the spectrum (6-10 p.p.m.) This behaviour is typical of the $\mathrm{C} 2$ and C4 protons of the imidazole ring of histidine residues (18). A diagram showing the variation of chemical shift as a function of $\mathrm{pH}^{*}$ is given in Figure 2. The chemical shift span over which these resonances titrate allows us to divide them into two groups; a-f with a span of $>0.6$ $\mathrm{ppm}$ and g-j with a span of $<0.5 \mathrm{ppm}$. The first group, to lower field, is assigned to the $\mathrm{C} 2$ protons and the second group to the $\mathrm{C} 4$ protons (18).

The resonances $b$ and $c$ overlap at all $\mathrm{pH}^{*}$ values at which spectra were obtained. The intensity of the peak labelled b, $c$, is twice that of the remaining resonances and thus corresponds to two protons.

The observation of six $\mathrm{C} 2$ protons is consistent with the sequence data which reveal the

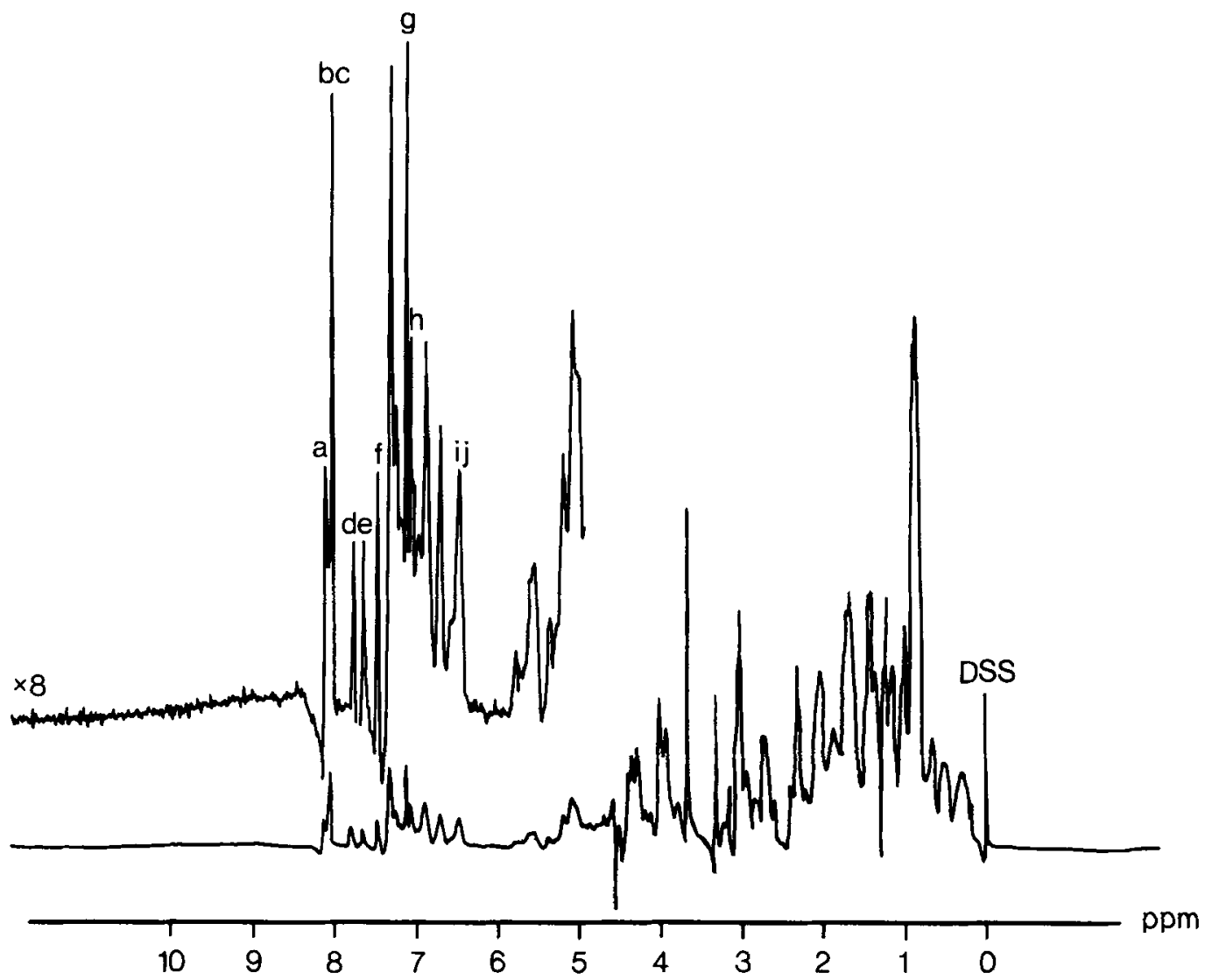

Figure 1. Convolution difference spectrum of apo yeast superoxide dismutase in $1 \mathrm{M}-\mathrm{NaCl}, 20 \mathrm{mM}$-phosphate, $\mathrm{pH}^{*}$ $6.7,40^{\circ} \mathrm{C}$. 
presence of six histidine residues in the protein!.

The reason that only four of the $\mathrm{C} 4$ protons can be assigned may be either that the span of chemical shifts on titrating is only half that of the $\mathrm{C} 2$ protons (18) so two peaks co-titrate at all $\mathrm{pH}^{*}$ values at which spectra were accumulated or that the overlap with the envelope of main aromatic intensity prevents adequate resolution even using difference spectra (17).

The curves shown in. Figure 2 do not represent the $\mathrm{pH}^{*}$ titration of isolated groups; that is they cannot be adequately fitted to a normal HENDERSON-HASSELBACH titration curve. This behaviour was also found in the $\mathrm{pH}^{*}$-titration of six $\mathrm{C} 2(\mathrm{H})$ resonances of apo bovine super-

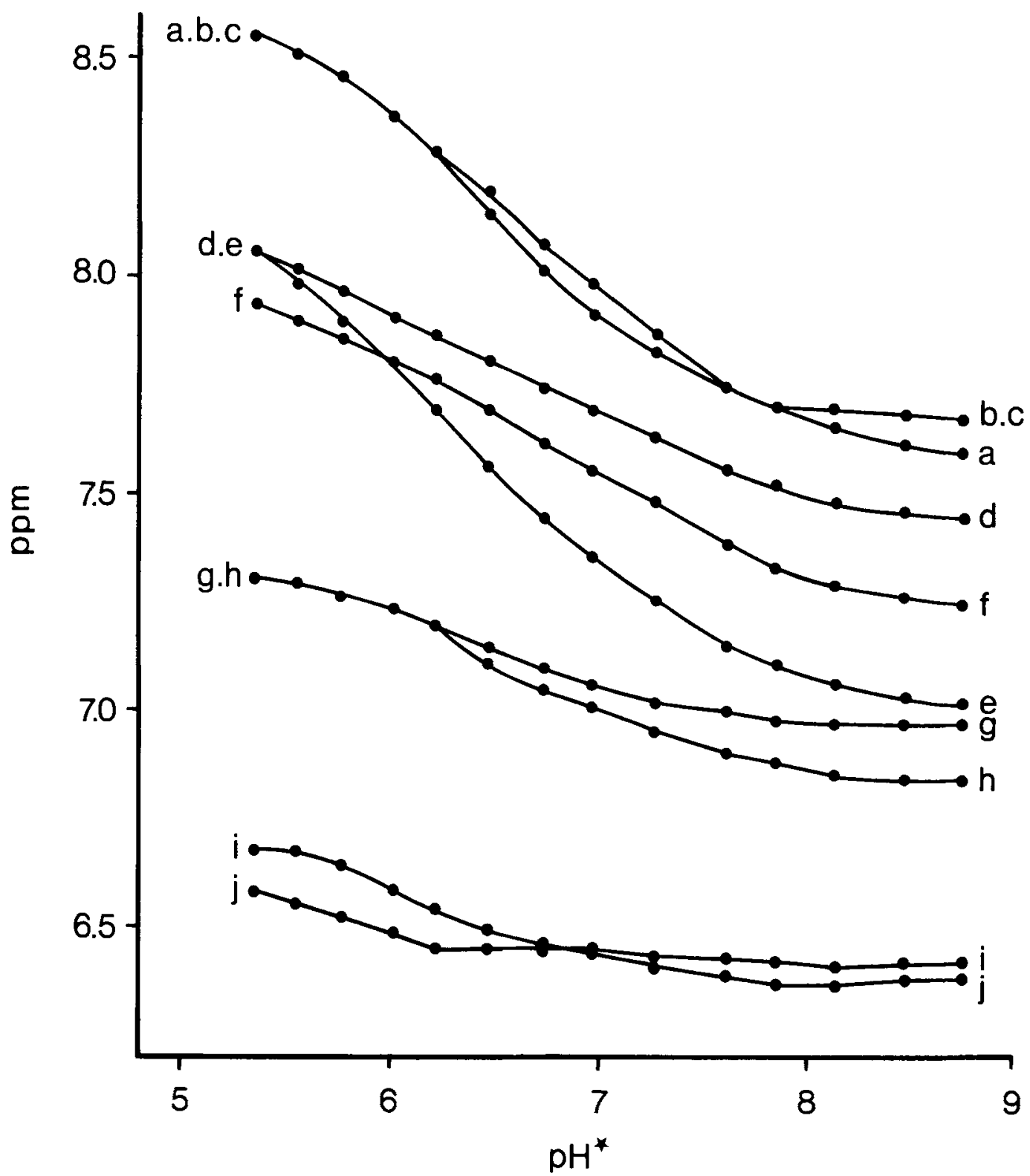

Figure 2. Effect of $\mathrm{pH}^{*}$ on chemical shifts of histidine $\mathrm{C} 2(\mathrm{H})$ and $\mathrm{C} 4(\mathrm{H})$ resonances in apo yeast superoxide dismutase at $40^{\circ} \mathrm{C}$, the lettering refers to Figure 1 . 
oxide dismutase (5) and this was interpreted as the mutual interaction of the histidine groups in the metal binding sites (5). The same explanation for the yeast enzyme implies that all histidine groups are in the metal binding sites. There are two other $\mathrm{C} 2(\mathrm{H})$ resonances in the ${ }^{1} \mathrm{H}$ n.m.r. spectrum of apo bovine superoxide dismutase, one of which titrated with a normal $\mathrm{pH}^{*}$ curve and was assigned to histidine 19 (5) and the other, which does not titrate at $\mathrm{pH}^{*}$ values below 7.5 and is rapidly deuterated (at $\mathrm{C2}$ ) above $\mathrm{pH}^{*} 7.5$, was assigned to histidine 41 (5, 6). In the yeast enzyme the ${ }^{1} \mathrm{H}$ n.m.r. spectra show that neither of these residues are present. This observation, and those decribed above, are consistent with the sequence where all six ligand histidines in the bovine enzyme are conserved in the yeast enzyme, whilst both histidines 19 and 41 have been substituted ${ }^{1}$.

\subsection{Copper (I)-zinc (II) enzyme}

The convolution difference spectrum of the holo enzyme, reduced with a minimal amount of sodium dithionite is shown in Figure 3. Com- parison of this spectrum with that of apo yeast superoxide dismutase (Figure 1) reveals a number of differences in both the aromatic and aliphatic regions. The most striking difference in the aliphatic region is the appearance, in the reduced holo enzyme, of a resonance $R$ located upfield of DSS at -0.24 p.p.m.

The resonance arises from a methyl group that has been shifted upfield by the ring currents of a nearby aromatic residue (8). The shift is very sensitive to the relative displacement and orientation of the methyl group and aromatic ring, and implies a specific structural change in the protein on binding the metals. There are other, less well-defined, changes throughout the aliphatic region, also consistent with a change in structure. This change in structure on binding the metals is very similar to the bovine enzyme, although in that case the resonance $R$ at -0.24 p.p.m. is not present (5). The origin of this resonance in the yeast enzyme may be due to the extra phenylalanine residues in the yeast enzyme ${ }^{1}$ or it may be due to a substitution close to one of the four phenylalanine residues common to both. A third alternative is that it is from

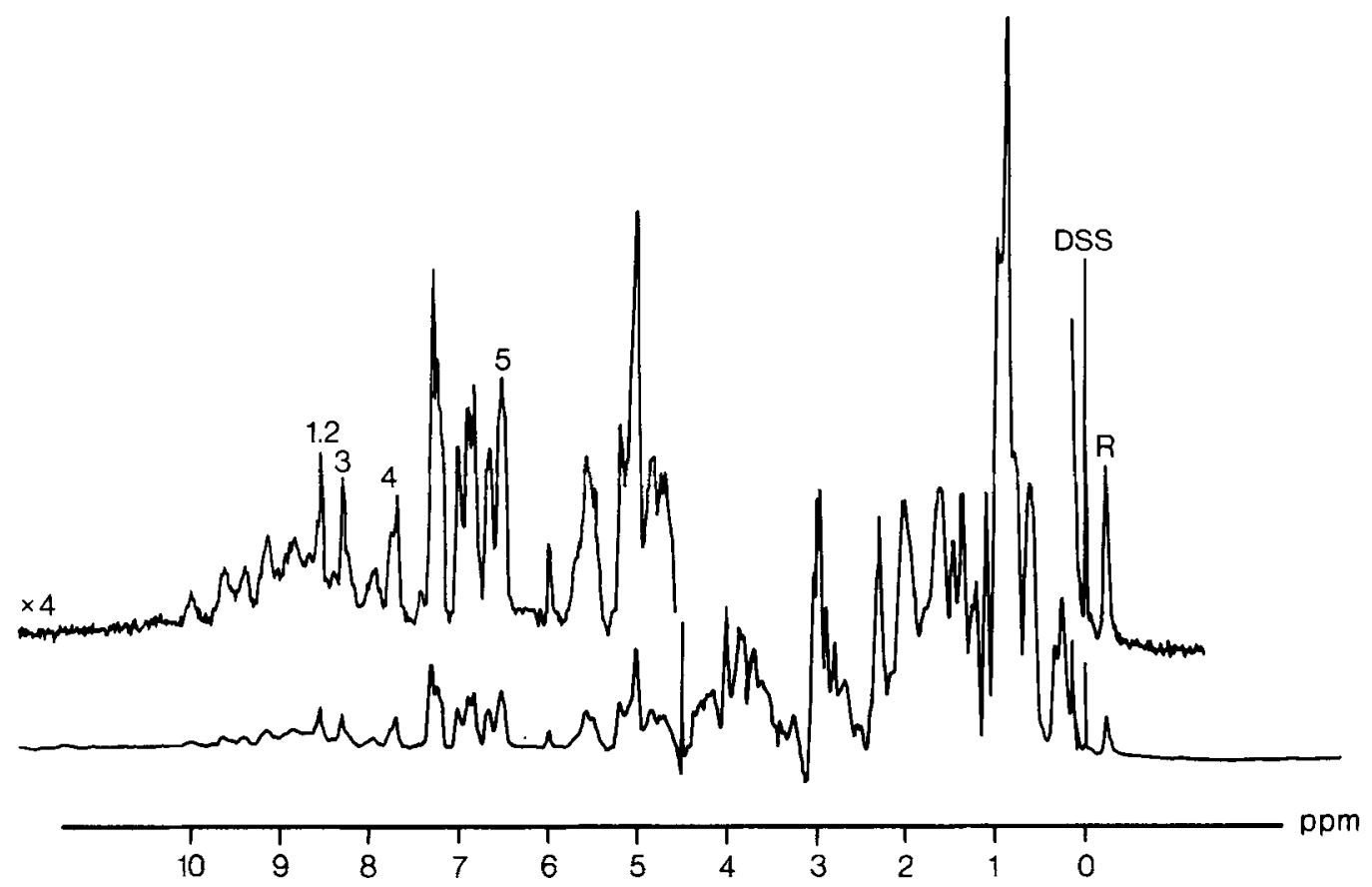

Figure 3. Convolution difference spectrum of copper(I)-zinc(II) superoxide dismutase in $1 \mathrm{M}-\mathrm{NaCl}, 20 \mathrm{mM}$ phosphate, $\mathrm{pH}^{*} 6.5,40^{\circ} \mathrm{C}$. 
a group close to the tyrosine residue in the yeast enzyme, which is in a very different position in the sequence compared to the bovine enzyme ${ }^{1}$ (22). Further, work with the bovine enzyme showed that the change in structure was due to the binding of zinc only (7). This conclusion is borne out by the present studies in which the addition of zinc to the yeast apo enzyme results in the appearence of resonance $\mathrm{R}$ with maximum intensity at one zinc per subunit.

When the spectrum of the apo enzyme is compared to that of the $\mathrm{Cu}(\mathrm{I})-\mathrm{Zn}$ (II) enzyme major changes are also visible in the aromatic region, mainly associated with histidine $\mathrm{C} 2$ and $\mathrm{C} 4$ proton resonances. The six resonances a-f, in the spectrum of the apo enzyme (Figure 1) are replaced by the five labelled $1-5$ in the reduced holo enzyme spectrum (Figure 3 ).

Resonances 1 and 2 overlap under these conditions though since the chemical shift of peak 2 is dependent on the anion present (vide infra), it is well separated from peak 1 in spectra obtained in $1 \mathrm{M}$-sodium perchlorate solution. Similarly the resonance labelled 5 in Figure 3 is shifted up into the main aromatic envelope in the presence of $1 \mathrm{M}$-sodium chloride and resolved in spectra of solutions in $1 \mathrm{M}$-sodium perchlorate. The unusually high field shift of this residue takes it well outside the usual $\mathrm{C} 2$ proton region. The assignment of this resonance to a ligand $\mathrm{C} 2$ proton is based partly on the effect of anions, described later, and partly on the results of selective deuteration experiments (unpublished results).

The $\mathrm{C} 2$ proton resonances of the $\mathrm{Cu}(\mathrm{I})-\mathrm{Zn}$ (II) enzyme show no $\mathrm{pH}^{*}$ dependent chemical shifts over the range $\mathrm{pH}^{*} 5-9$. We have previously argued (5) that this change in $\mathrm{pH}^{*}$ titration behaviour upon binding metals to the apo enzyme is strong evidence in favour of histidine residues acting as metal ligands. Our results therefore imply that all six histidine residues in yeast superoxide dismutase are metal ligands. This is consistent both with the sequence comparison of the yeast ${ }^{1}$ and bovine enzyme (26), the known metal ligands in the latter, and with the explanation offered above for the unusual titration behaviour of the histidine resonances in the apo enzyme.

The other resonances that we have assigned in the yeast enzyme are from the ring protons of the tyrosine residue. These resonances were as-

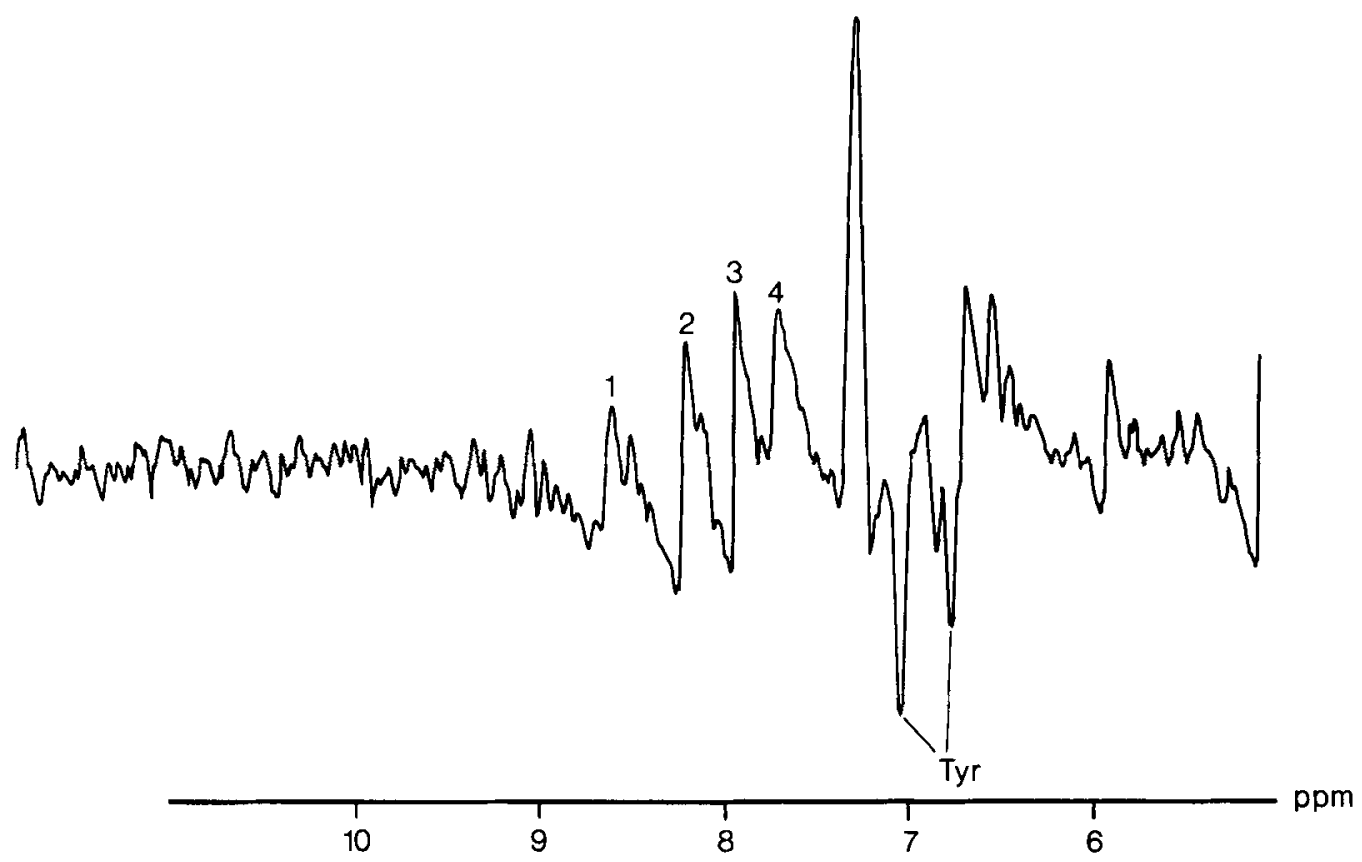

Figure 4. Spin echo spectrum of copper(I)-zinc(II) yeast superoxide dismutase $1 \mathrm{M}-\mathrm{NaCl}, 20 \mathrm{mM}$-phosphate, $\mathrm{pH}^{*} 6.5,75^{\circ} \mathrm{C}$. 
signed using the 90- $\tau-180-\tau-[$ Collect] spin-echo pulse sequence and for $\tau=\frac{1}{2 J}$ doublets are $180^{\circ}$ out of phase with respect to singlets and triplets (4). This method will only work if $2 \tau<T_{2}$ where $T_{2}$ is the spin-spin relaxation time of the protons; for yeast superoxide dismutase the spin echo spectrum is shown in Figure 4, and the two doublets from the ring protons of tyrosine are marked. In order to obtain this spectrum the sample had to be heated to $75^{\circ} \mathrm{C}$ to increase $\mathrm{T}_{2}$ sufficiently, and it is interesting that the protein retains its low temperature conformation under these conditions. This is most clearly seen with peak $R$, as ring current shifted resonances have a chemical shift that is intrinsically independent of temperature (8). If a shift is observed it is due to the change in the relative geometry of the shifted group and the aromatic ring, and this has been used to follow the thermal unfolding of lysozyme (19). In holo reduced yeast superoxide dismutase the peak $R$ still maintains its position at -0.24 p.p.m. at $75^{\circ} \mathrm{C}$. Similarly by measuring spectra at various temperatures from $40^{\circ} \mathrm{C}$ to $75^{\circ} \mathrm{C}$ we can observe that the peaks assigned to the tyrosine residue at $75^{\circ} \mathrm{C}$ have the same chemical shift at $40^{\circ} \mathrm{C}$.

\subsection{Comparison of resonance positions in bovine and yeast superoxide dismutase}

The chemical shift of a particular nucleus can be considered as arising from the effect of nearby atoms or groups which influence the electron density via the chemical bonds. In addition the microenvironment can influence the chemical shift "through space ". For example the former is illustrated by the fact that the $\mathrm{C} 2$ proton of a histidine residue occurs at lower field than the corresponding $\mathrm{C} 4$ proton, whilst an example of the latter is the occurrence of ring current shifts. It is essentially the latter which is sensitive to the tertiary structure of the protein.

Table I compares the chemical shifts of the four assigned ligand histidine $\mathrm{C} 2$ protons in the bovine enzyme with the five in the yeast enzyme. The data for the ring protons of the tyrosine residue are also included. The final column in this Table is the expected position for the residue in a random coil (20). The similarity between the chemical shifts in the yeast and bo-
Table I

Comparison of chemical shifts in p.p.m. of histidine and tyrosine protons in $\mathrm{Cu}(\mathrm{I})-\mathrm{Zn}$ (II) superoxide dismutase from bovine erythrocytes, yeast and in a random coil proton. The enzymes were dissolved in $1 \mathrm{M}$-sodium chloride at $\mathrm{pH}^{*} 6.8$.

\begin{tabular}{|c|c|c|c|}
\hline Resonance & Bovine (5) & Yeast & Random coil (20) \\
\hline Histidine $\mathrm{C} 2(\mathrm{H})$ & 8.58 & 8.54 & \\
\hline - & 8.47 & 8.59 & \\
\hline - & 8.33 & 8.30 & 7.90 \\
\hline - & 7.72 & 7.70 & \\
\hline- & - & 6.50 & \\
\hline Tyrosine (o) & 7.01 & 7.05 & 7.09 \\
\hline Tyrosine (m) & 6.67 & 6.77 & 6.82 \\
\hline
\end{tabular}

The correlations between histidine $\mathrm{C} 2$ proton chemical shifts are based on this work and unpublished studies of the effects of halide anions on the bovine enzyme.

vine enzymes suggests a very similar microenvironment at the active site. Despite their very different positions in the sequence ${ }^{1}(22)$ the tyrosine residues also yield resonances which have similar chemical shifts. The values of the latter differ little from those expected for a random coil protein suggesting that in both the yeast and bovine enzymes these tyrosine residues are on the surface of the molecule.

\subsection{Copper (II)-zinc (II) enzyme}

The convolution difference spectrum of the oxidized holo enzyme is shown in Figure 5. In considering the effect of the paramagnetic copper (II) ion on the proton relaxation times in the bovine enzyme it was shown that a resonance should be "broadened beyond detection" if the proton is closer than $\sim 13 \AA$ to the copper (5). This result is consistent with the structure of the enzyme revealed by $\mathrm{X}$-ray diffraction techniques (6). A very similar limit will also apply to the yeast enzyme. Thus we can see that with the copper(II)-zinc(II) enzyme the spectrum shows complete loss of all the histidine $\mathrm{C} 2$ proton intensity, consistent with their role as metal ligands. The tyrosine ring protons are still detectable and must be further than $\sim 13 \AA$ from the copper. The ring current shifted methyl group 


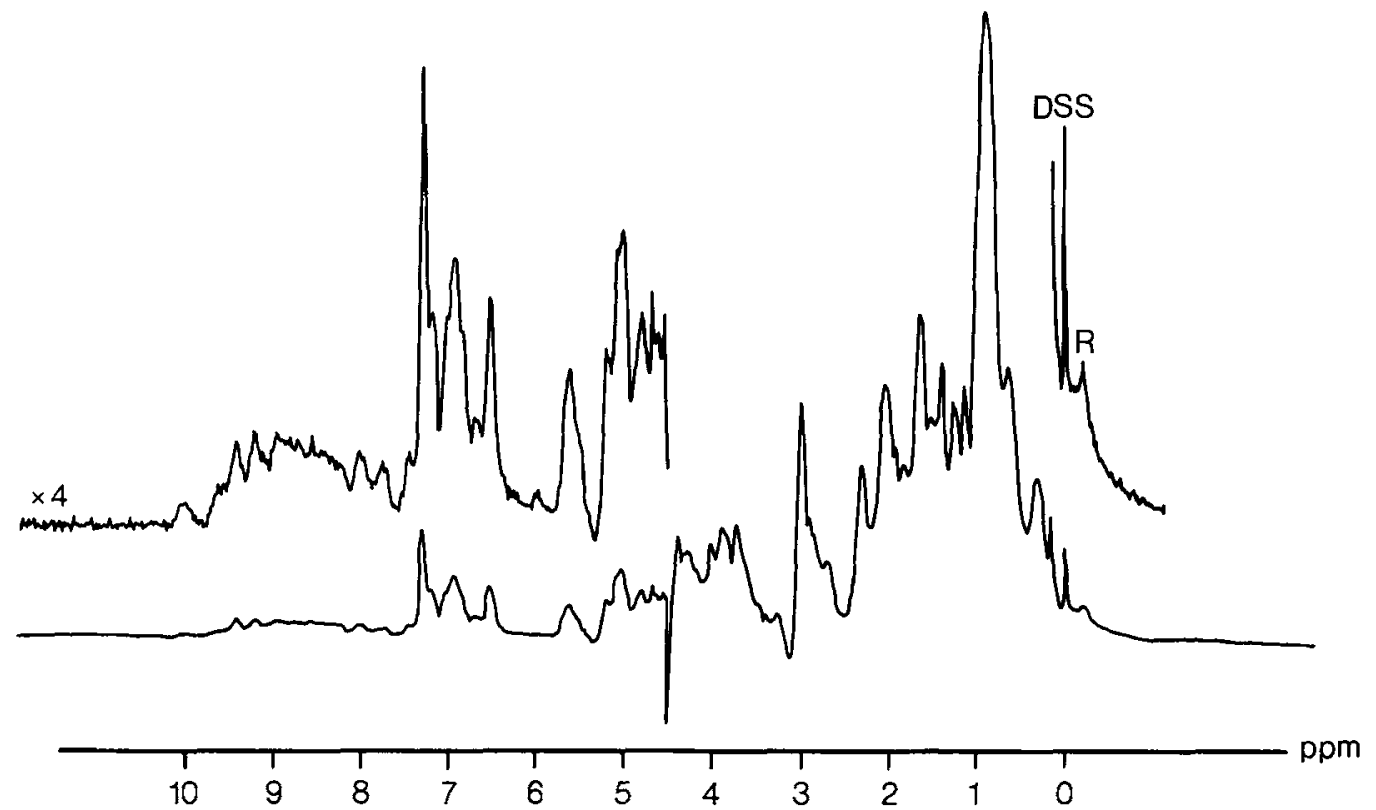

Figure 5. Convolution difference spectrum of copper(II)-zinc(II) superoxide dismutase in $1 \mathrm{M}-\mathrm{NaCl}, 20 \mathrm{mM}$ phosphate, $\mathrm{pH}^{*} 6.5,40^{\circ} \mathrm{C}$.

(resonance $R$ in Figure 3 ) has been substantially broadened although there is some residual intensity. This implies that it is some 14-20 A from the copper.

\subsection{Effect of anions on the reduced enzyme}

Several studies with bovine superoxide dismutase have shown that monovalent anions will bind to the copper ion. FEE and GABER (12) showed that addition of $\mathrm{CN}^{-}$or $\mathrm{N}_{3}^{-}$perturbed the electron paramagnetic resonance (e.p.r.) spectrum of the copper and reduced the relaxivity of the water protons. FEE and WARD (13) used ${ }^{35} \mathrm{Cl} \mathrm{n.m.r.} \mathrm{to} \mathrm{show} \mathrm{that} \mathrm{Cl}^{-}$was in fast exchange (with respect to the ${ }^{35} \mathrm{Cl}$ relaxation time) with the reduced enzyme. Recently Rigo et al. (25) showed that $\mathrm{F}^{-}, \mathrm{Cl}^{-}, \mathrm{Br}^{-}, \mathrm{N}_{3}^{-}$and $\mathrm{CN}^{-}$ were competitive inhibitors of the bovine enzyme and also increased the $T_{1}$ (spin-lattice relaxation time) of the water protons in the presence of the oxidized enzyme. We therefore decided to try and selectively perturb the environment of the ligand histidines by adding monovalent anions.

Figure 6 shows that ${ }^{1} \mathrm{H}$ n.m.r. spectrum of
$\mathrm{Cu}(\mathrm{l})-\mathrm{Zn}$ (II) yeast superoxide dismutase in $\mathrm{I}$ M-sodium perchlorate solution. If this is compared to Figure 3 it can be seen that the chemical shifts of three of the five histidine $\mathrm{C} 2$ protons have changed. The spectra of the enzyme in mixtures of chloride and perchlorate show that the chloride is in fast exchange between the bulk solution and a site on the protein.

\subsubsection{Analysis of chloride binding}

The observed chemical shift of a resonance in the presence of chloride, if the chloride is in fast exchange is (8):

$$
\delta=\delta_{\mathrm{b}} \frac{\left[\mathrm{ECl}^{-}\right]}{\left[\mathrm{E}_{\mathrm{T}}\right]}+\delta_{\mathrm{f}} \frac{[\mathrm{E}]}{\left[\mathrm{E}_{\mathrm{T}}\right]}
$$

where $\delta$ is the observed chemical shift, $\delta_{b}$ is the chemical shift in the fully formed complex and $\delta_{f}$ is the chemical shift in the absence of chloride. $\left[\mathrm{ECl}^{-}\right],[\mathrm{E}]$ and $\left[\mathrm{E}_{\mathrm{T}}\right]$ are the concentration of the enzyme-chloride complex, free enzyme and total enzyme respectively. Also

$$
\frac{\left[\mathrm{ECl}^{-}\right]}{\left[\mathrm{E}_{\mathrm{T}}\right]}+\frac{[\mathrm{E}]}{\left[\mathrm{E}_{\mathrm{T}}\right]}=1
$$




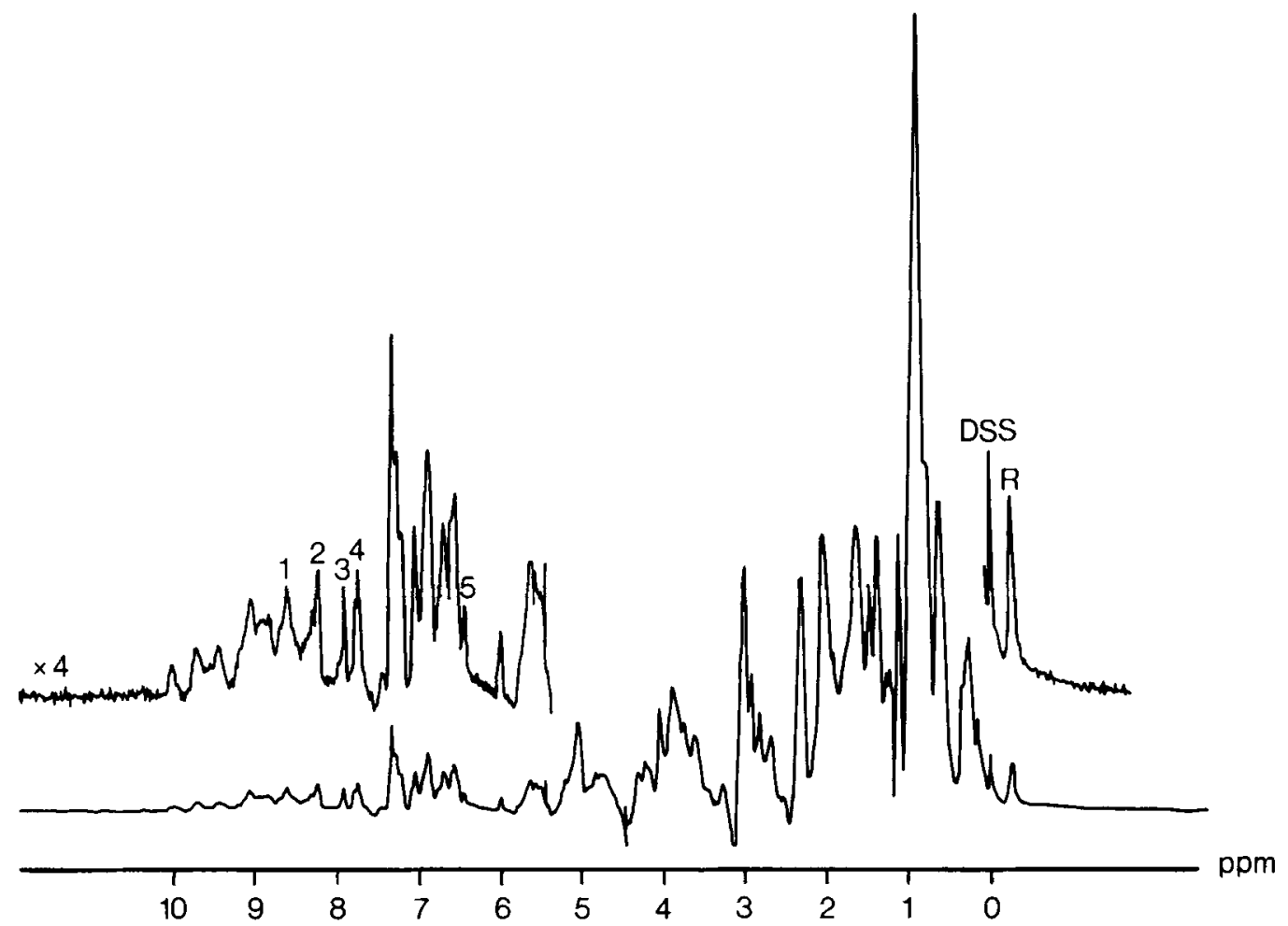

Figure 6. Convolution difference spectrum of copper(I)-zinc(II) yeast superoxide dismutase in $1 \mathrm{M}-\mathrm{NaClO}_{4}$, $20 \mathrm{~mm}$-phosphate, $\mathrm{pH}^{*} 6.5,40^{\circ} \mathrm{C}$.

Equations [1] and [2] can be combined to yield equations [3] and [4]

$$
\begin{gathered}
\frac{[E]}{\left[E_{T}\right]}=\frac{\delta_{-} \delta_{b}}{\delta_{f^{-}} \delta_{b}}=\frac{\delta_{b^{-}} \delta}{\delta_{b^{-}} \delta_{f}} \\
\frac{\left[E c l^{-}\right]}{\left[E_{T}\right]}=\frac{\delta_{f^{-}} \delta}{\delta_{f^{-}} \delta_{b}}=\frac{\delta_{-} \delta_{f}}{\delta_{b^{-}} \delta_{f}}
\end{gathered}
$$

Dividing [3] by [4] yields

$$
\frac{[\mathrm{E}]}{\left[\mathrm{ECl}^{-}\right]}=\frac{\delta_{\mathrm{b}^{-}}-\delta}{\delta_{-} \delta_{\mathrm{f}}}=\frac{\mathrm{K}_{\mathrm{d}}}{\left[\mathrm{Cl}^{-}\right]}
$$

If $\Delta=\delta-\delta_{\mathrm{f}}$ the observed shift from the position in the absence of chloride and $\Delta_{0}=\delta_{b}-\delta_{f}$ the total span then

$$
\frac{\mathrm{K}_{\mathrm{d}}}{\left[\mathrm{Cl}^{-}\right]}=\frac{\Delta_{\mathrm{o}}-\Delta}{\Delta}=\frac{\Delta_{\mathrm{o}}}{\Delta}-1
$$

B Rown et al. have shown that an equation of this form holds for $\mathrm{pH}$ titration behaviour (2) and these authors used the direct linear plot method (9) to analyze their results. The same procedure can be used here if $\left[\mathrm{Cl}^{-}\right] \cong\left[\mathrm{Cl}_{\mathrm{T}}^{-}\right]$, as $\left[\mathrm{Cl}_{\mathrm{T}}\right] \geqq 250 \mathrm{~mm}$ and $\left[\mathrm{E}_{\mathrm{T}}\right] \sim 5 \mathrm{mM}$ this is obviously the case.

The analysis of the chloride binding, by the direct linear plot method, for resonances 2, 3 and 5 , gives dissociation constants of $1.7,1.0$ and $2.4 \mathrm{M}$ respectively. The maximum titration shifts are $0.87,0.86$ and 0.11 p.p.m., respectively; these results are consistent with the chloride binding at a single site and perturbing the histidines $3 \sim 2>5 \gg 1 \sim 4$.

\subsubsection{Other anions}

Table II summarizes the effect of halide anions, all at a concentration of $1 \mathrm{M}$, on the histidine $\mathrm{C} 2$ proton resonances of reduced yeast superoxide dismutase. The magnitude of the 
Table II

Chemical shifts in p.p.m. of histidine $\mathrm{C} 2$ protons in $\mathrm{Cu}(\mathrm{I})-\mathrm{Zn}$ (II) yeast superoxide dismutase in the presence of various anions. In all these experiments the protein was prepared in the presence of a $1 \mathrm{M}$-solution of the anion at $\mathrm{pH}^{*}$ 6.9-7.0 and a temperature of $40^{\circ} \mathrm{C}$.

\begin{tabular}{lccccc}
\hline & \multicolumn{5}{c}{ Resonance } \\
Anion & 1 & 2 & 3 & 4 & 5 \\
\hline $\mathrm{ClO}^{-}$ & 8.57 & 8.20 & 7.88 & 7.75 & 6.42 \\
$\mathrm{~F}^{-}$ & 8.61 & 8.28 & 8.00 & 7.76 & 6.45 \\
$\mathrm{Cl}^{-}$ & 8.59 & 8.54 & 8.30 & 7.76 & 6.50 \\
$\mathrm{Br}^{-}$ & 8.55 & 8.55 & 8.31 & 7.74 & 6.53 \\
$\mathrm{I}^{-}$ & 8.57 & 8.36 & 8.04 & 7.73 & 6.44 \\
\hline
\end{tabular}

shifts is in every case $3 \sim 2>5 \gg 1 \sim 4$; and the effectiveness of the anions is $\mathrm{Cl}^{-} \sim \mathrm{Br}^{-}>\mathrm{I}^{-}>\mathrm{F}^{-}$. In contrast to the results of Rigo et al. (25) with the bovine enzyme we have found that iodide will bind to the reduced form of the yeast enzyme.

Our observation of three histidines being perturbed when anions bind is consistent with the presumed coordination in the bovine enzyme (24) if the interposed histidine 61 is not coordinated to the reduced copper, as has been suggested by others. This histidine must also be sufficiently divorced from the copper site not to be affected by replacing a coordinated water by a chloride ion.

The n.m.r. evidence presented in this paper supports the thesis that the structure of yeast superoxide dismutase is similar to that of the bovine enzyme and that the active site has the same geometry.

\section{ACKNOWLEDGEMENTS}

The authors wish to thank EDITH FLøISTRUP at the Carlsberg Laboratory for technical assistance. A.E.G.C. would like to thank the U. K. Science Research Council and V. H. would like to thank EMBO and the Carlsberg Laboratory for financial support. This is a joint contribution from the Oxford Enzyme Group of which H.A.O.H. is a member and the Department of Chemistry of the Carlsberg Laboratory.

\section{REFERENCES}

1. Barra, D., F. Martini, F. Bossa, G. Rotilio, J. V. Bannister, \& W. H. Bannister: Primary structure of human copper-zinc superoxide dismutase. Cysteine- and tryptophan-containing peptides. Biochem. Biophys. Res. Commun. 81, 1195-1200 (1978)

2. Browne, C. A., I. D. Campbell, P. A. Kiener, D. C. Phillips, S. G. Waley \& I. A. Wilson: Studies of the histidine residues of triose phosphate isomerase by proton magnetic resonance and $\mathrm{X}$-ray crystallography. J. Mol. Biol. 100, 319-343 (1976)

3. Cambell, I. D., C. M. Dobson, R. J. P. Williams \& A. V. XAVIER: Resolution enhancement of protein PMR spectra using the difference between a broadened and a normal spectrum. J. Magn. Resonance 11, 172-181 (1973)

4. Campbell, I. D., C. M. Dobson, R. J. P. Williams \& P. E. WRIGHT: Pulse methods for the simplification of protein n.m.r. spectra. FEBS Letters 57, 96-99 (1975)

5. CAss, A. E. G, H. A. O. Hill, B. E. SMith, J. V. BANNISTER \& W. H. BANNISTER: Investigation of the structure of bovine erythrocyte superoxide dismutase by ${ }^{1} \mathrm{H}$ nuclear magnetic resonance spectroscopy. Biochemistry 16, 3061-3066 (1977)

6. Cass, A. E. G., H. A. O. Hill, B. E. Sмith, J. V. Bannister \& W. H. Bannister: Carbon-2- proton exchange at histidine- 41 in bovine erythrocyte superoxide dismutase. Biochem. J. 165, $587-589$ (1977)

7. Cass, A. E. G., H. A. O. Hill, J. V. Bannister \& W. H. BANNISTER: Zinc(II) binding to apo bovine erythrocyte superoxide dismutase. Biochem. J. (in press)

8. DWEK, R. A.: Nuclear magnetic resonance (N. M. R.) in biochemistry. Oxford University Press, Oxford pp. 48-54 (1973)

9. EISENTHAL, R. \& A. CORNISH-BOWDEN: The direct linear plot. A new graphical procedure for estimating enzyme kinetic parameters. Biochem. J. 139, 715-720(1974)

10. Farrar, T. C. \& E. D. Becker: Pulse and fourier transform NMR, Academic Press, New York and London (1971)

11. FEe, J, A.: Structure-function relationships in superoxide dismutases. In: Superoxide and superoxide dismutases, A. M. Michelson, J. M. McCord \& I. Fridovich, eds., Academic Press, London, New York and San Fransisco, pp. 173-192 (1977)

12. Fee, J. A. \& B. P. Gaber: Anion binding to bovine erythrocyte superoxide dismutase. J. Biol. Chem. 247, 60-65 (1972) 
13. FEe, J, A. \& R. L. WARD: Evidence for a coordination position available to solute molecules on one of the metals at the active center of reduced bovine superoxide dismutase. Biochem. Biophys. Res. Commun. 71, 427-437 (1976)

14. Fridovich, I.: Superoxide dismutases. Adv. Enzymol. 41, 35-47 (1974)

15. FRIDOviCH, I.: Superoxide dismutases. Ann. Rev. Biochem. 44, 147-159 (1975)

16. Harris, J. I. \& H. M. Steinman: Amino-acid sequence homologies among superoxide dismutases. In: Superoxide and superoxide dismutases, A. M. Michelson, J. M. McCord \& I. Fridovich, eds., Academic Press, London, New York and San Francisco, pp. 225-230 (1977)

17. KING, N. L. R. \& J. H. BradbuRY: Simplification of the proton magnetic resonance spectrum of ribonucleases by difference spectroscopy. Nature (London) 229, 404-406 (1971)

18. Markley, J. L.: Observation of histidine residues in proteins by means of nuclear magnetic resonance spectroscopy. Acc. Chem. Res. 8, 70-80 (1975)

19. McDonald, C. C. \& W. D. Phillips: Manifestations of the tertiary structures of proteins in highfrequency nuclear magnetic resonance. J. Am. Chem. Soc. 89, 6332-6341 (1967)

20. McDonald, C. C. \& W. D. Phillips: Proton magnetic resonance spectra of proteins in ran- dom-coil configurations. J. Am. Chem. Soc. 91, 1513-1521 (1969)

21. Michelson, A. M., J. M. MCCoRD \& I. FRIDOviCH, eds.: Superoxide and superoxide dismutases. Academic Press, London, New York and San Francisco, (1977)

22. Petersen, C., V. hasemann, B. Martin, J. T. JohANSEN, I. SVENDSEN \& M. OTteSEN: The amino terminal sequence of superoxide dismutase from Saccharomyces cerevisiae. Carlsberg Res. Commun. 42, 391-395 (1977)

23. RichaRdSON, D. C.: The three-dimensional structure of $\mathrm{Cu}, \mathrm{Zn}$ superoxide dismutase. In: Superoxide and superoxide dismutases, A. M. Michelson, J. M. McCord \& I. Fridovich, eds., Academic Press, London, New York and San Francisco, pp. 217-223 (1977)

24. Richardson, J. S., K. A. Thomas, B. H. Rubin \& D. C. Richardson: Crystal structure of bovine $\mathrm{Cu}, \mathrm{Zn}$ superoxide dismutase at $3 \AA$ resolution: Chain tracing and metal ligands. Proc. Nat. Acad. Sci. USA, 72, 1349-1353 (1975)

25. Rigo, A., R. Stevanato, P. Viglino \& G. RotiLlo: Competitive inhibition of $\mathrm{Cu}, \mathrm{Zn}$ superoxide dismutase by monovalent anions. Biochem. Biophys. Res. Comun. 79, 776-783 (1977)

26. Steinman, H. M., R. N. Vishweshwar, J. L. ABERNETHY \& R. L. HILL: Bovine erythrocyte superoxide dismutase. Complete amino acid sequence. J. Biol. Chem. 249, 7326-7338 (1974) 